\title{
Knowledge and Practice of Personal Hygiene and Sanitation: A Study in Selected Slums of Dhaka City
}

\author{
Shayela Farah ${ }^{1}$, Mohoshina Karim², Nasreen Akther ${ }^{3}$, Meherunnessa Begum ${ }^{4}$, Nadia Begum ${ }^{5}$
}

\begin{abstract}
Background: : Slum dwellers are likely to be among the most deprived people in urban areas. Poor hygiene practices and inadequate sanitary conditions play major roles in the increased burden of communicable diseases within developing countries like ours. Objective: To assess the knowledge and practice about personal hygiene and environmental sanitation in selected slums of Dhaka city. Materials and method: This cross sectional study was conducted in purposively selected urban slum areas of Moghbazar slum, Bashabo slum and T\&T slum of Dhaka city during February 2014 to April 2014. Convenient sampling technique was applied. Semi-structured pre-tested questionnaire was used and face to face interview was conducted. Total 475 subjects, irrespective of age and sex, were included in this study. Results: Out of 475 respondents, more than fifty percent slum dwellers resided in tin shaded room while $21.7 \%$ in ' $k$ acha' houses. Sixty six percent of the respondents used to drink water from tube-well and $24 \%$ used supplied water provided by the city corporation. The study revealed that near 59\% of the respondents used sanitary latrine. About $67 \%$ slum dwellers regularly practiced hand washing before taking meal and 59.2\% respondents used soap after defecation. About fifty percent respondents brushed their teeth regularly with tooth paste. Regarding personal cleanliness, $81 \%$ subjects took bath regularly while $78 \%$ washed clothes irregularly. A statistically significant relation was found between washing of hands before meal ( $p=0.001)$, washing of hands after defecation $(p=0.02)$, tooth brushing $(p=0.001)$, bathing $(p=0.009)$, washing of cloths $(p=0.001)$, use of footwear $(p=0.63)$ with knowledge of personal hygiene of the slum dwellers. Conclusion: Continuous community hygiene education along with adequate access to water supply and sanitation improves hygiene behaviour and policy makers and health care providers should have definite strategy and implementation.
\end{abstract}

Keywords: Hygiene; sanitation; slum; urban.

Delta Med Col J. Jul 2015;3(2):68 - 73

\section{Introduction}

Bangladesh has experienced one of the highest urban population growth rates $(>6 \%$ per year) in the last three decades compared to the national population growth rate of about $1.5 \%$ per year.

1. Assistant Professor, Department of Community Medicine, Dhaka Community Medical College, Dhaka, Bangladesh.

2. Lecturer, Department of Community Medicine, Dhaka Community Medical College, Dhaka, Bangladesh.

3. Assistant Professor, Department of Community Medicine, Ibn Sina Medical College, Dhaka, Bangladesh.

4. Assistant Professor, Department of Community Medicine, Ibn Sina Medical College, Dhaka, Bangladesh.

5. Assistant Professor, Department of Community Medicine, Z.H. Sikder Medical College, Dhaka, Bangladesh.

Correspondence: Dr. Shayela Farah. e-mail: shayelafarah@yahoo.com 
Slum dwellers have also increased in number tremendously and are likely to be among the most deprived people in urban areas. ${ }^{1}$

In South Asia 39 percent of the population is living in absolute poverty, with an income of less than one US dollar a day. According to the Household Income and Expenditure Survey (HIES) 2010, the poverty rate of Bangladesh has dropped to 31.5 per cent in 2010, reflecting an 8.5 percentage point decline in the last five years. ${ }^{2}$ Safe water is one of the most important felt needs in public health in developing countries in the twenty first century. ${ }^{3}$ The year 2005 marked the beginning of the "International Decade for Action: Water for Life" and renewed effort to achieve the Millennium Development Goal (MDG) to reduce by half the proportion of the world's population without sustainable access to safe drinking water and sanitation by $2015 .{ }^{4}$ It is estimated by World Health Organization (WHO) and United Nations International Children's Emergency Fund (UNICEF) that 1.1 billion people lack access to improved water supplies and 2.6 billion people lack adequate sanitation. ${ }^{5}$

A large number of people in Bangladesh lack access to portable drinking water. Among them, urban slum dwellers face the greatest challenges. Their water quality is affected by unsafe water supply, unhygienic sanitation facilities, and poor solid waste management, unhygienic practices particularly with regard to hand washing, insecure land tenure, poor socio-economic backing, and crowded living conditions. However in recent study it has been found that in Dhaka alone there are about 5000 slums and the total slum population is about 3.4 million. ${ }^{6}$ The people from these high-risk areas often suffer from diarrhoea and other water borne diseases. Due to lack of education, knowledge and basic awareness, people often have a poor understanding of the relationship between health, water, sanitation and hygiene. In some instances, people may still practice unhygienic habits even though this understanding does exist. ${ }^{7}$
Over $37 \%$ of the city populations live in slums that occupy only $4 \%$ of city land. Slums are the most densely populated areas with over 200 times the normal density of Bangladesh at 531,000 persons per square mile. Overcrowding creates huge increase in communicable diseases like diarrhoea. ${ }^{8}$ About $24 \%$ of urban households are estimated to have no sanitary latrines. In pockets such as slums, sanitary latrine coverage is even lower than the average of $14 \%$ for towns and cities. Furthermore, over $80 \%$ of the low income populations have no legal access to safe water. Hanging latrines and indiscriminate garbage dumping by households, industries, clinics, etc. are very common in the urban areas. ${ }^{7}$ As elsewhere in the Third World, slums and squatters in Bangladesh attracted not much attention from the public health policy makers. Studies on the effects of environmental factors on slum dwellers health in the context of Bangladesh are scarce. ${ }^{9}$ According to the World Health Organization (WHO) the main determinants of health include the social and economic environment, the physical environment, and the person's individual characteristics and behaviours. Personal hygiene is the practice of maintaining cleanliness of the body, it is done through bathing, hair grooming, and hand washing, brushing teeth, trimming nails and cleaning ears among others. Through these personal behaviours, social acceptances are gained. However maintaining good or acceptable personal hygiene is seldom perceived and acknowledged as protection against diseases. ${ }^{10} \mathrm{It}$ is now high time to put focus on aspects of hygiene practices and sanitation as defined in national health care and sanitation strategy. That's why, essential goal of the study is to find out personal hygiene practices and sanitation facilities in urban slum dwellers in Dhaka city.

\section{Materials and method}

This cross sectional study was designed to assess the knowledge and practice of personal hygiene and sanitation conducted in purposively selected 
three urban slums of Dhaka city during February 2014 to April 2014. The target population consisted of individuals living in Moghbazar slum, Bashabo slum and T\&T slum of Dhaka city. A total of 475 slum dwellers were purposively enrolled for the study. A semi structured pre-tested questionnaire was used to collect data from face to face interview. Information regarding the type of house/room, source of drinking water, knowledge about activities of personal hygiene, monthly income and level of education were collected. Verbal informed consent was taken from the respondents by explaining the purpose of the study. Collected data were analysed by SPSS (Statistical Package of Social Science), version-17, Windows software programme.

\section{Knowledge score}

Here knowledge related hygienic questions in the questionnaire were four in number. The respondents' knowledge was scored using a scoring system. ${ }^{11}$ All questions had three parts yes, no, don't know. Each correct response under knowledge attracted one point, whereas any wrong or don't know answer attracted no mark. This gave a total score of 12 points for knowledge. Respondents that scored 0-4 points were adjudged as having poor knowledge; whereas those that scored 5-8 and 9-12 were adjudged as having fair and good knowledge respectively.

\section{Results}

\section{Residential facilities in slum area}

Regarding housing conditions, more than fifty percent resided in tin shaded room/house and 103 $(21.7 \%)$ in 'kacha' house. Sixty six percentages of the respondents used to drink water from tube-well and $24 \%$ used supplied water by the city corporation. The study showed that 279 (59\%) of the respondents used sanitary latrine, 191 (40\%), insanitary latrine and remaining used open air latrines (Table I).
Table I: Residential facilities in slum area $(\mathrm{N}=475)$

\begin{tabular}{lcc}
\hline Variables & Frequency & Percentage \\
\hline Type of house & 103 & 21 \\
Kacha & 84 & 17 \\
Semi-pucca & 29 & 06 \\
Pucca & 259 & 55 \\
Tin & & \\
Sources of water & 110 & 24 \\
$\quad$ Supply water & 315 & 66 \\
Tube well & 45 & 09 \\
Deep tube well & 05 & 01 \\
Others & & \\
Types of latrine & 279 & 59 \\
Sanitary latrine & 191 & 40 \\
Insanitary latrine & 05 & 01 \\
Open air latrine & & \\
\hline
\end{tabular}

Profiles of activities of personal hygiene practices of the study subjects

Out of 475 respondents, 320 (67\%) slum dwellers regularly practiced hand washing with soap before taking meal whereas $281(59.2 \%)$ respondents used soap, $144(30.3 \%)$ used only water after defecation as hand washing purpose. Near fifty percent respondents brushed their teeth regularly with tooth paste and the rest 135 (28\%), 84 (18\%), $38(8 \%)$, used tooth powder, ash, and neem stick respectively. Regarding personal cleanliness, 387 $(81 \%)$ subjects took bath regularly and on the other hand $370(78 \%)$ respondents washed cloths irregularly (Table II).

Table II: Distribution of respondents' personal hygiene practices $(N=475)$

\begin{tabular}{lcc}
\hline Personal hygiene habit & Frequency & Percentage \\
\hline Hand washing before taking meal & & \\
$\quad$ Using of soap & 320 & 67 \\
Using water only & 110 & 23 \\
$\quad$ Irregular using of soap water & 45 & 10 \\
Hand washing after defecation & & \\
$\quad$ Using of soap & 281 & 59.2 \\
Using water only & 144 & 30.3 \\
Irregular using of soap water & 50 & 10.5 \\
Tooth brushing habit & & \\
$\quad$ Tooth paste & 218 & 46 \\
Tooth powder & 135 & 28 \\
Ash & 84 & 18 \\
$\quad$ Neem stick & 38 & 08 \\
Bathing & & \\
Regular & 387 & 81 \\
Irregular & 88 & 19 \\
Washing of cloths & & \\
Irregular & 370 & 22 \\
Regular & 105 &
\end{tabular}




\section{Relationship between education and personal hygiene practice of the respondents}

Chi-square test was done taking activities of personal hygiene practice (washing of hands before meal, washing of hands after defecation, tooth brushing, bathing, washing of cloths, use of footwear) as dependent variables and knowledge of hygiene as independent variable. Analysis revealed significant negative association between washing of hands before taking meal $(\mathrm{p}=0.001)$, washing of hands after defecation $(\mathrm{p}=0.02)$, tooth brushing ( $p=0.001)$, bathing $(p=0.009)$, washing of cloths $(p=0.001)$, but no relation with use of footwear $(p=0.63)$ with knowledge of personal hygiene of the slum dwellers (Table III).

Table III: Relationship between education and personal hygiene practice of the respondents $(\mathrm{N}=475)$

\begin{tabular}{llcccc}
\hline \multicolumn{1}{c}{ Variables } & & Frequency (\%) & Frequency $(\%)$ & $\chi^{2}$ & p-value \\
\hline $\begin{array}{l}\text { Washing of hands } \\
\text { before meal }\end{array}$ & Yes & $144(46.0)$ & $169(54.0)$ & 12.82 & 0.001 \\
& No & $47(29.0)$ & $115(71.0)$ & & \\
Washing of hands & Yes & $110(45.3)$ & $133(54.7)$ & & \\
after defecation & No & $81(34.9)$ & $151(65.1)$ & & 0.02 \\
& & & & & \\
Tooth brushing & Yes & $52(60.5)$ & $34(39.5)$ & 17.92 & 0.001 \\
& No & $139(35.7)$ & $250(64.3)$ & & \\
Bathing & Regular & $182(42.0)$ & $251(58.0)$ & 6.76 & 0.009 \\
& Irregular & $9(21.4)$ & $33(78.6)$ & & \\
Washing of cloths & Regular & $36(29.5)$ & $86(70.5)$ & 11.23 & 0.001 \\
& Irregular & $146(46.9)$ & $165(53.1)$ & & \\
Use of footwear & Yes & $74(41.6)$ & $104(58.4)$ & \multirow{2}{*}{0.22} & 0.63 \\
& No & $117(39.4)$ & $180(60.6)$ & & \\
\hline
\end{tabular}

\section{Discussion}

This cross-sectional study was conducted to assess the knowledge and practice of personal hygiene and sanitation in three selected slums of Dhaka city. A total of 475 subjects were included. We found that more than fifty percent respondents resided in tin shaded room/house and $21.7 \%$ in 'kacha' house. Similar observations were observed by an NGO - Democracywatch. ${ }^{12}$ The use of tube-well water was $66 \%$ and $24 \%$ respondents used supplied water provided by the city corporation for cooking and other purposes.
Whereas $61.21 \%$ of slum dwellers in Rajshahi collected drinking water from the community tube well, and about $34 \%$ had individual tube wells; and a small minority of people $(3.3 \%)$ had a water connection. ${ }^{9}$

From the study, it was revealed that majority $(59 \%)$ of the respondents used sanitary latrine. But Raihan et al. ${ }^{13}$ mentioned that near one-fourth $(22 \%)$ of the respondents used sanitary latrine and about $58 \%$ used kacha and $20 \%$ used open latrines. The differences regarding the use of sanitary latrine may be due difference in study area.

Regarding personal hygiene practices, we found that $67 \%$ slum dwellers practiced hand washing before taking meal and about 59\% respondents washed hand with soap after defecation which was similar with the study done in north Jordan. ${ }^{14} \mathrm{We}$ also found that near fifty percent respondents brushed their teeth regularly with tooth paste and the rest used tooth powder, ash, neem stick, etc. Similar findings were observed in southern India ${ }^{15}$ and north Jordan. ${ }^{14}$ Regarding personal cleanliness, $81 \%$ subjects took bath regularly and $78 \%$ washed cloths irregularly. In an Ethiopian study approximately $34 \%$ of the respondents reported poor bathing practices and $21 \%$ reported poor hair washing practices. ${ }^{16}$ These findings are in concurrence with a study conducted in the Philippines which found that $35 \%$ of respondents reported poor bathing. ${ }^{17}$ Based on these results, it appears that the hygiene practices which require the greatest amount of water result in lower rates of practice. Both bathing and washing require relatively larger volumes of water. Since obtaining water is a challenge in rural and urban slum settings, it is a common practice for families to ration and re-use their supply. Thus, personal hygiene becomes a low priority when water is scarce. Rather than use water for personal cleanliness, families prioritize their use of available water for drinking, cooking, washing clothes, and household cleaning. ${ }^{18}$ In this study we found that education and knowledge about hygiene is intimately and significantly associated with practice of personal hygiene. 


\section{Conclusion}

In developing countries, slum is quite common. Practically slums have become almost an integral part of big cities. Poverty, unemployment, landlessness, inequality in economic development, low wages, etc. in the rural areas are thought to be responsible to magnetize people towards city and facilitate to erect slum neighbourhood. This unabated urbanization process causes diverse troubles to the slum dwellers. Continuous community hygiene education along with physical access to water supply and sanitation positively influences change in hygiene behaviour. We therefore recommend that an implementation strategy and plan for the Hygiene Awareness Package should be developed by public health care providers as well as the policy makers so that we can achieve substantial decrease in communicable diseases due to poor hygiene practice.

\section{References}

1. Uddin J, Koehlmoos TL, Ashraf A, Khan AI, Saha NC, Choudhury AI, et al. Health Needs and Health-seeking Behaviours of Street Dwellers in Dhaka City. ICDDR,B, 2008. Working paper no.:167.

2. Kabir HMH. Poverty Rate Now. The Financial Express, Dhaka, Bangladesh. 2011 April 30:31.5pc.

3. Sah RB, Baral DD, Ghimire A, Pokharel PK. Study on Knowledge and Practice of Water and Sanitation Application in Chandragadhi VDC of Jhapa District. Health Renaissance. 2013;11(3):241-45.

4. World Health Organization (WHO), United Nations Children's Fund (UNICEF) Joint Monitoring Programme on Water Supply and Sanitation (JMP): Report of the First Meeting of the Advisory Group; 2004 October 5-7; Geneva [electronic resource]; 2004 [cited 2009 June 10]. Available from: http://www.bvsde.paho.org/CD-GDWQ/Biblioteca/ Manuales_Guias_LibrosDW/JMP/JMP/JMP_TAG_ 3_report.pdf.

5. Moe CL, Rheingans RD. Global Challenges in Water, Sanitation and Health. J Water Health. 2006; $4(1): 41-57$.
6. Dana T. Unhygienic Living Conditions and Health Problems: A Study in Selected Slums of Dhaka City; Ontario International Development Agency. International Journal of Sustainable Development. 2011 [cited 2015 June 10];02:11. Available from: http://www.ssrn.com/link/OIDA-Intl-Journal-Sustai nable-Dev.html.

7. Das R, Ghosh G, Singha D. Participatory Community Hygiene Education in Dhaka Slums: DSK Experience. South Asia Hygiene Practitioners' Workshop; 2010 Feb; Dhaka, Bangladesh [cited 2015 June 10]. Available from: http://www. wsscc.org/sites/default/files/publications/5_ranajitd as_hygieneeducationdhakaslums_bangladesh_2010. pdf.

8. Centre for Urban Studies (CUS), National Institute of Population Research and Training (NIPORT), MEASURE Evaluation. Slums of Urban Bangladesh Mapping and Census 2005. 2006 May; Bangladesh and Chapel Hill, USA; p.10-11.

9. Hossain MA, Moniruzzaman M, Islam MA. Urban Environmental Health in Bangladesh Slum: A Comparative Study of Two Metropolitan Cities. J Sci Foundation. 2010;8(1\&2):67-76.

10. Asha Rai MG. Promotion of Health and Hygiene among School Children by Health Education. Voice of Research. 2013;1(4):44-46.

11. Ekanem EE, Gbadeyesin A. Voluntary Counselling and Testing (VCT) for Human Immunodeficiency Virus: A Study on Acceptability by Nigerian Women Attending ANC. Afr J Reprod Health. 2004;8(2):91-100.

12. Rehman T. Health Problems of Women Living in Slums: A Situation Analysis of Three Selected Slums in Dhaka City. 14th Batch Participants of Gender and Governance Training Program of Democracywatch. 2014.

13. Raihan $\mathrm{MMH}$, Islam $\mathrm{MN}$, Rouf $\mathrm{A}$, Begum $\mathrm{A}$, Rahman MM, Murad MS, et al. Health Care Situation of Migrant Slum Women: Evidence from Sylhet City of Bangladesh. Bangladesh e-Journal of Sociology [Internet]. 2014 [cited 2015 June 10];11(1):119-34. Available from: http://www. bangladeshsociology.org/Health\%20Care\%20Situat ionBEJS\%2011.1.pdf. 
14. Inter-Agency Knowledge, Attitudes and Practices Study of Syrian Refugees in Host Communities in North Jordan. Study Report. 2013 [cited 2015 June 10]. Available from: http://data.unhcr.org/ syrianrefugees/download.php.

15. Gupta T, Sequeira P, Acharya S. Oral Health Knowledge, Attitude and Practices of a 15-year-old Adolescent Population in Southern India and Their Social Determinants. Oral Health Prev Dent. 2012;10(4):345-54.

16. Vivas A, Gelaye B, Aboset N, Kumie A, Berhane Y, Williams MA. Knowledge, Attitudes, and Practices
(KAP) of Hygiene among School Children in Angolela, Ethiopia. J Prev Med Hyg. 2010;51(2):73-79.

17. Department of Health Republic of the Philippines. Personal Hygiene [cited 2009 July 10]. Available from: http://www.doh.gov.ph/h1n1/images/dm2009 -0113.pdf.

18. Oswald WE, Hunter GC, Lescano AG, Cabrera L, Leontsini E, Pan WK, et al. Direct Observation of Hygiene in a Peruvian Shantytown: Not Enough Hand Washing and Too Little Water. Trop Med Int Health. 2008;13:1421-28. 